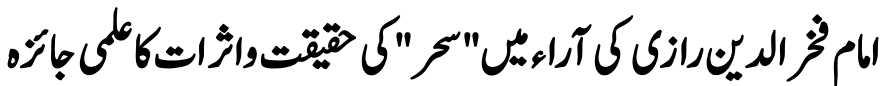

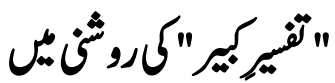

\section{Magic - Its Nature and Role in the Light of "Tafseer Kabeer" of Imam Fakhr-ud-Din Razi}

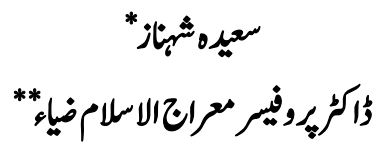

\begin{abstract}
Black magic or sehar (Arabic) refers to a practice or an art in which an individual uses satanic powers to achieve the impossible, their own or other's evil designs, and harm or dupe others. It is an art that can be taught and acquired .With the help of satanic and evil forces ,this art is acquired through great efforts, and requires repudiation of all that is in the Quran and the Sunnah to gain the favor of the supernatural forces, such as Satan and Jinnat. This paper is an attempt to study the truth of this practice in the light of (a) The Quran and Sunnah (b) the saying of the Four Imam (c) the viewpoint of Imam Fakhruddin Razi in Tafseer-e-Kabeer. It includes that (1) the effect of sehar depends on whether Allah wills it or not; and the one who practices Black Magic is considered an apostate whereas the one under the effect of sehar has their reward; and (2) practicing Black Magic is a great sin which may lead to a Muslim magician's eviction from Islam which is punishable by death according to the four school of thoughts of Islam.
\end{abstract}

Keywords: Magic, Tafseer Kabeer, Fakhr-ud-din Razi.

$$
\begin{aligned}
& \text { سك ع نوى متن: }
\end{aligned}
$$

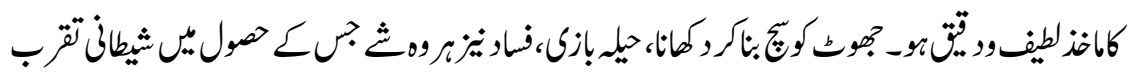

$$
\begin{aligned}
& 1 \text { - }
\end{aligned}
$$

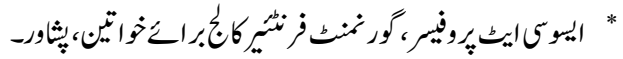

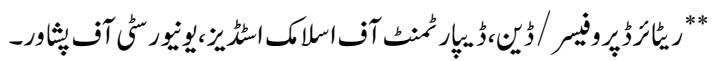




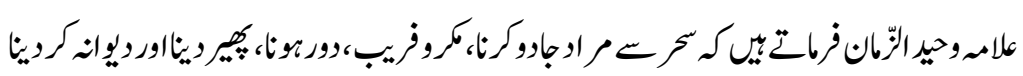

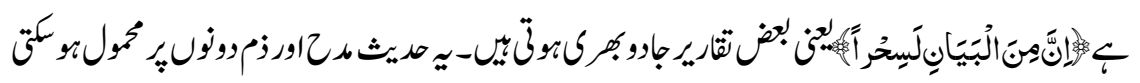

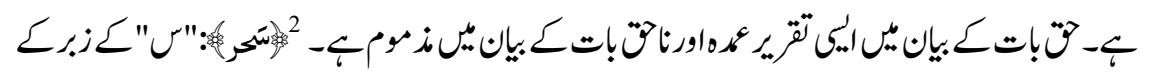

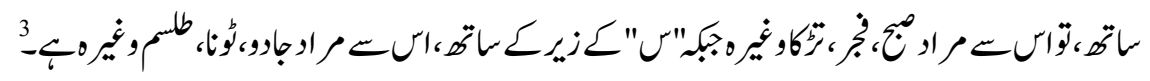

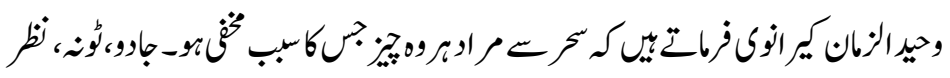

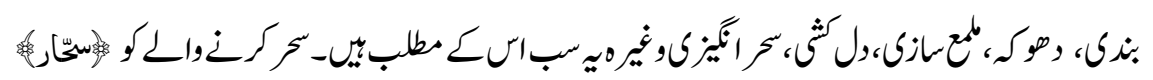

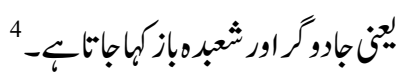

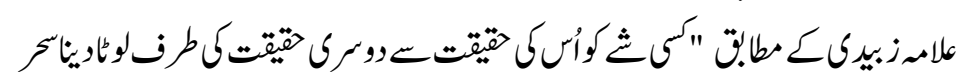

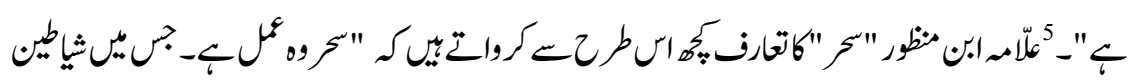

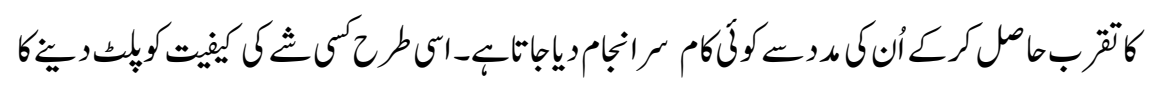

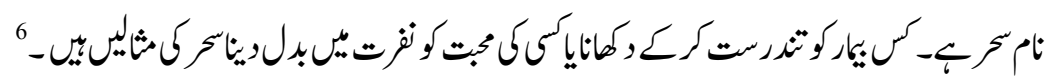

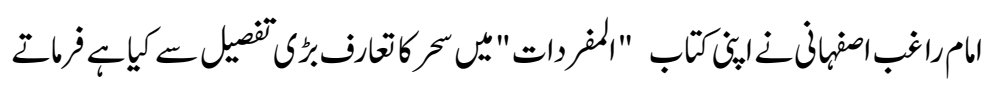

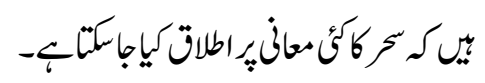

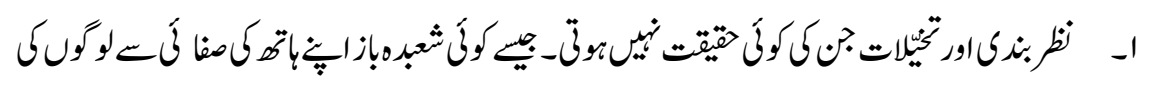

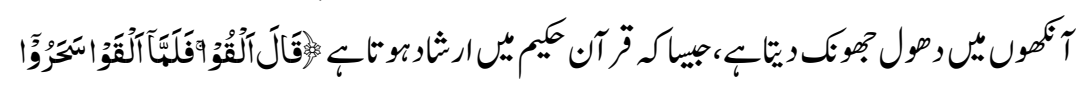

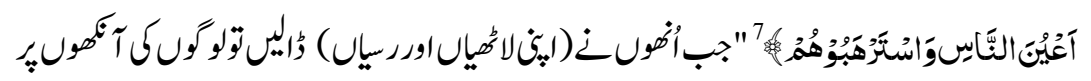

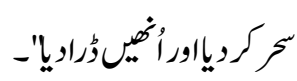

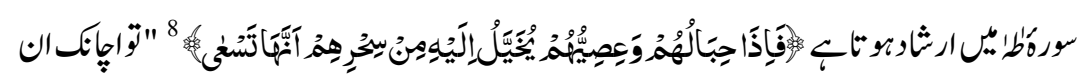

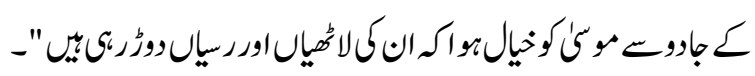

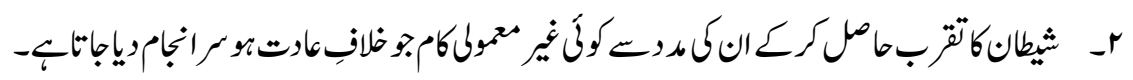

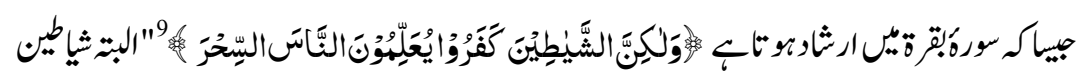

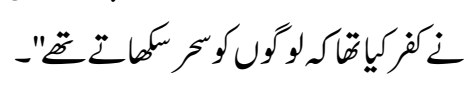

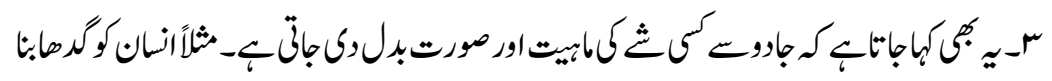

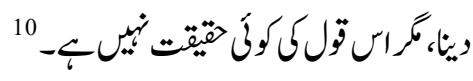




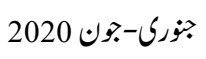

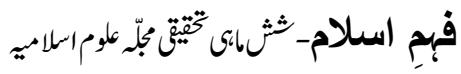

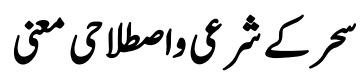

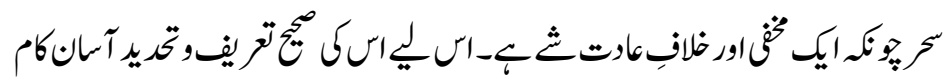

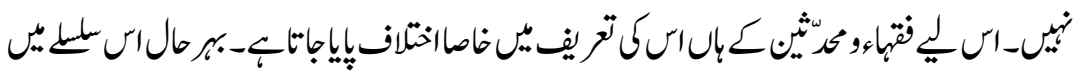

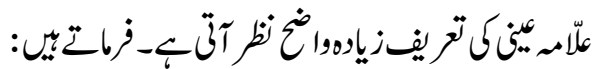

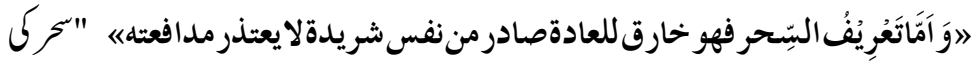

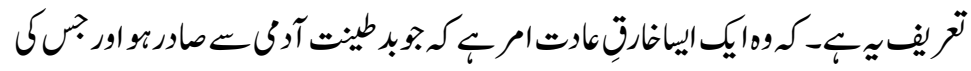

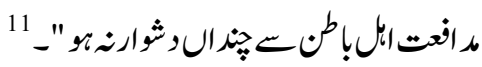

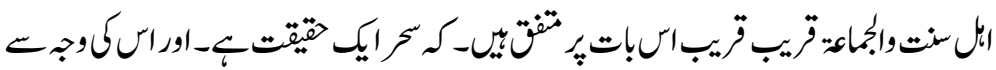

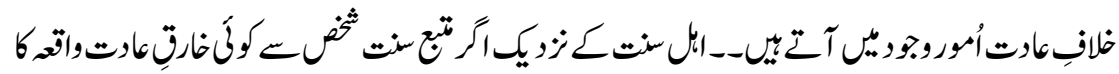

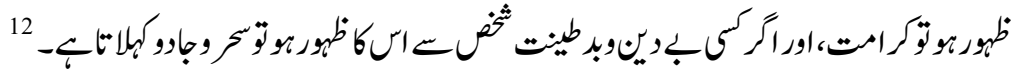

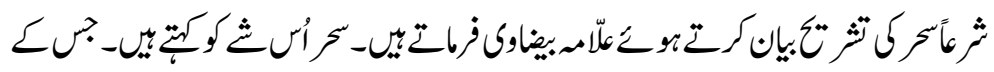

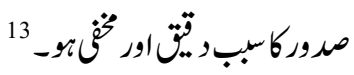

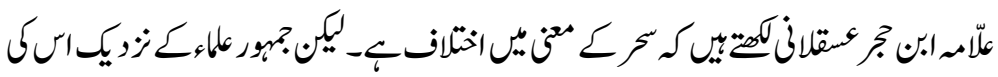

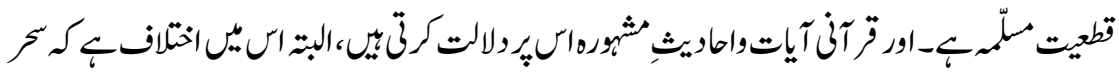

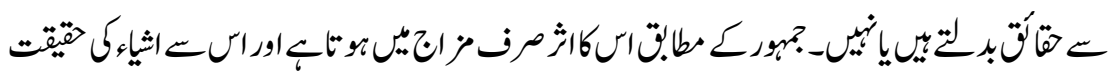

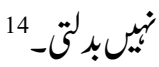

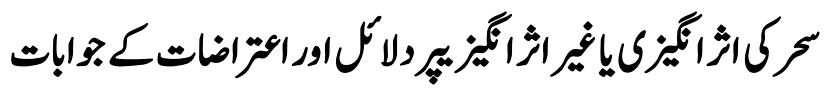

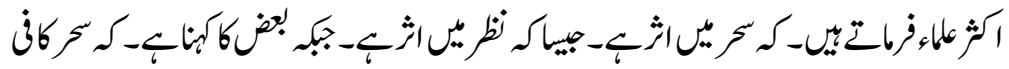

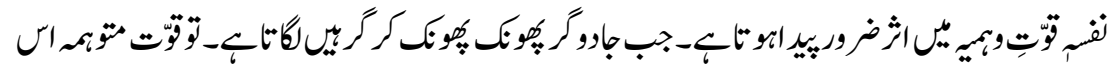

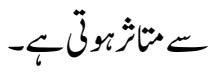

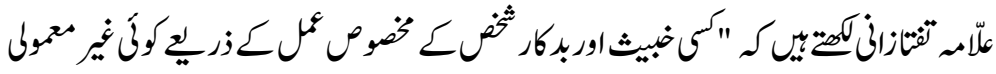

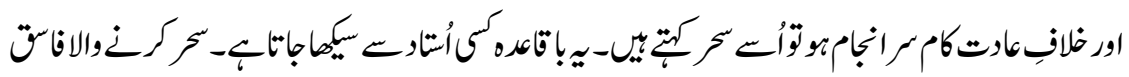

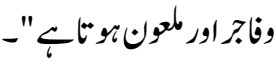

3 


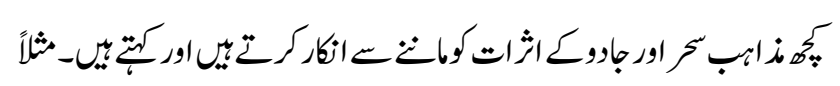

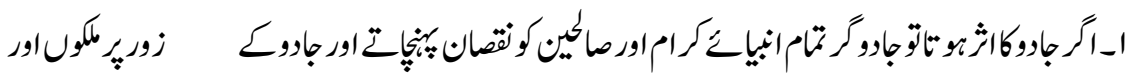

$$
\text { سلطنوير كومت كركا }
$$

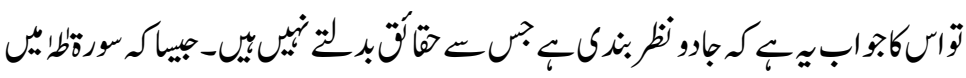

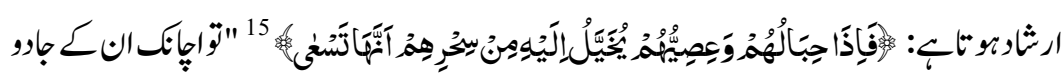

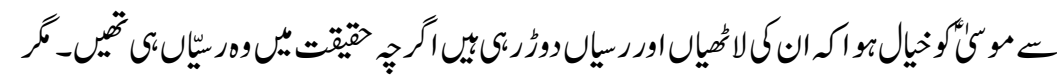

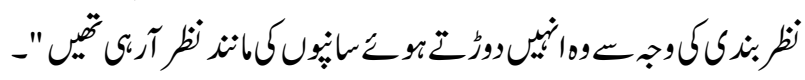

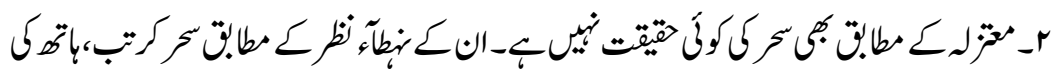

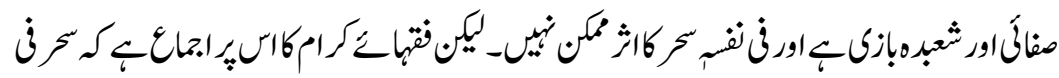

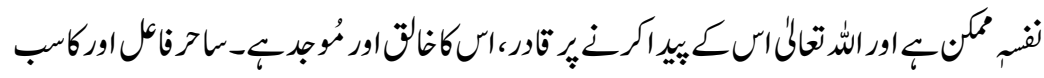

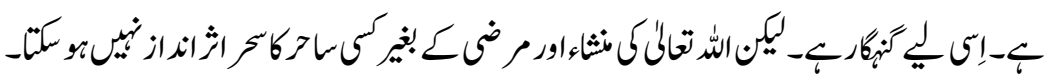

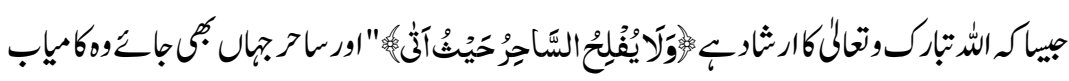

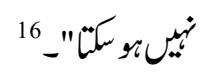

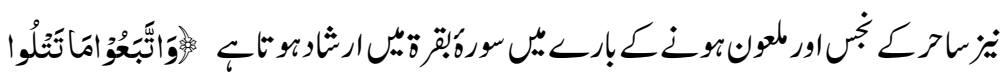

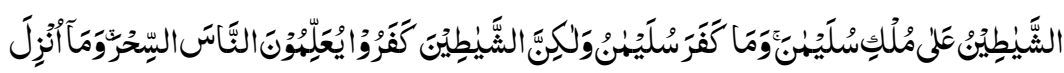

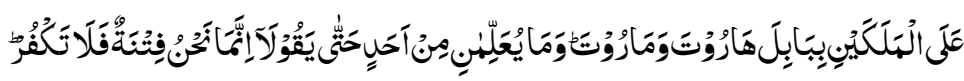

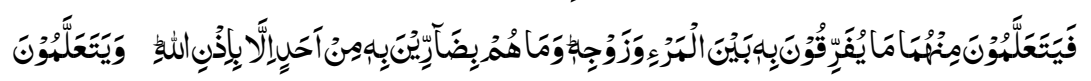

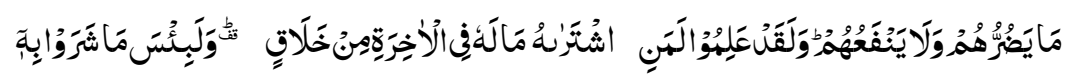

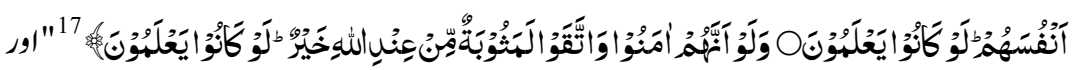

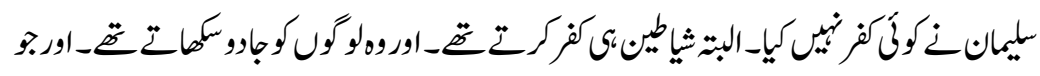

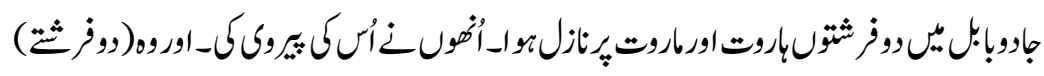

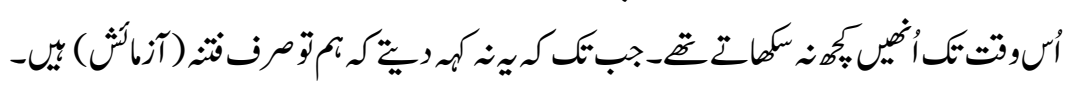

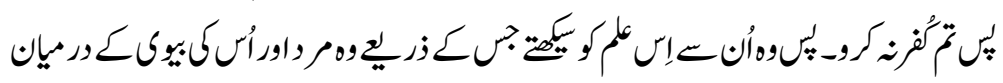

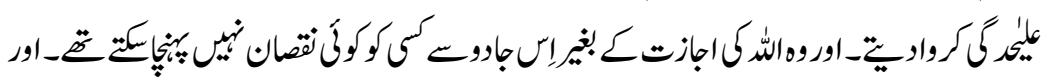




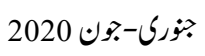

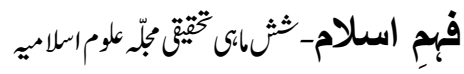

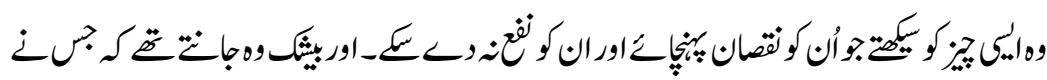

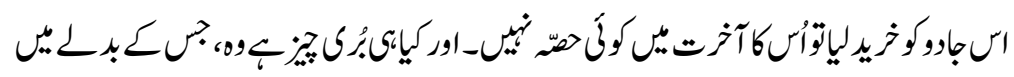

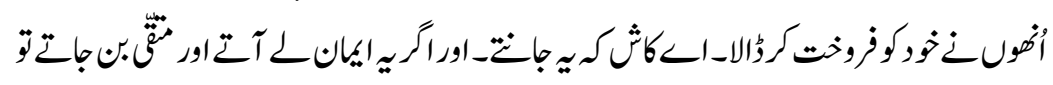

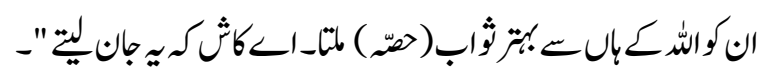

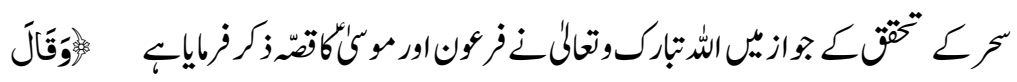

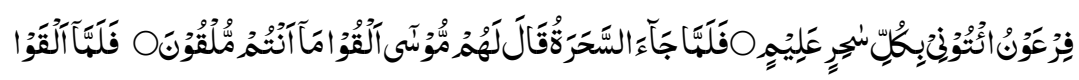

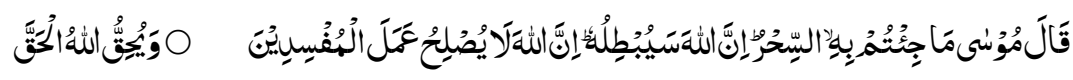

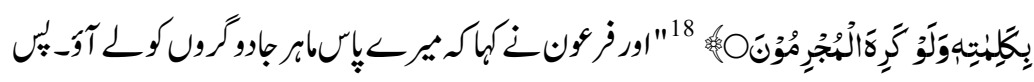

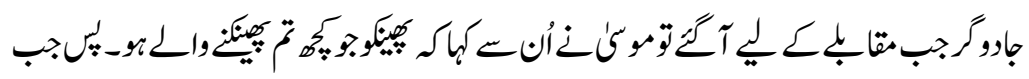

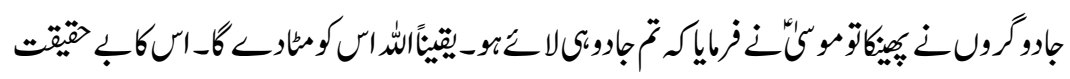

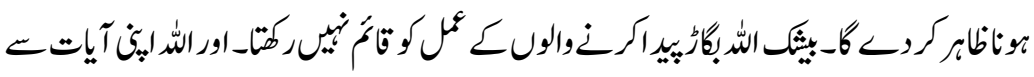
توكمجاويتاب

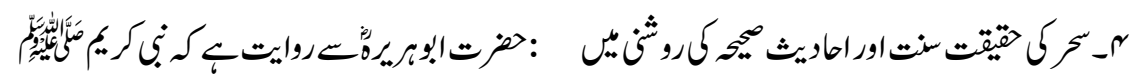

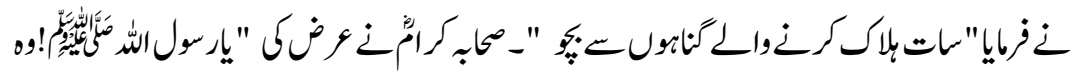

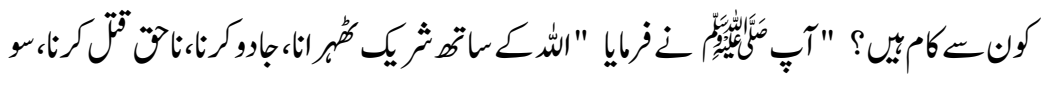

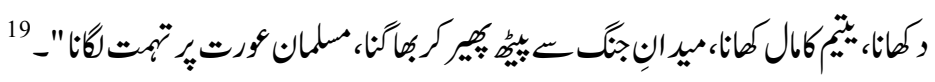

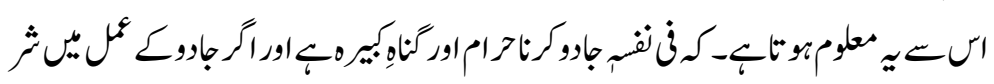

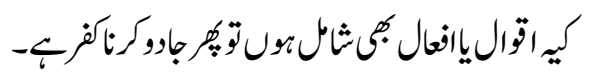

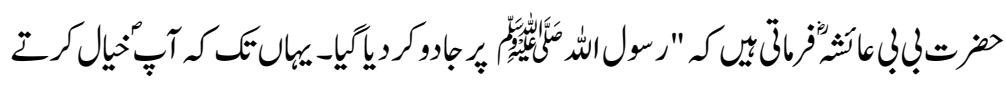

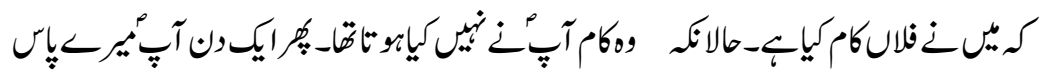

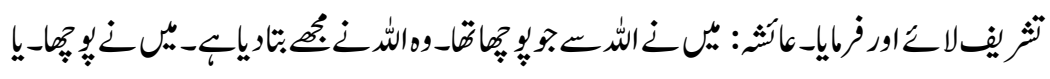

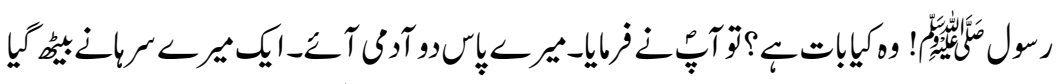

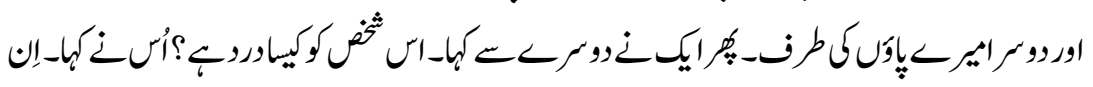

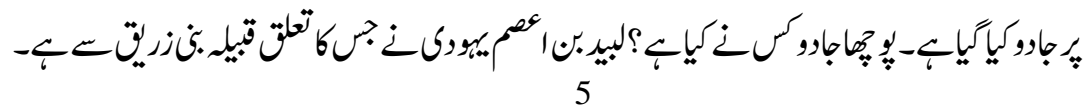




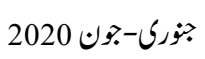

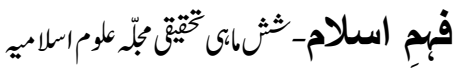

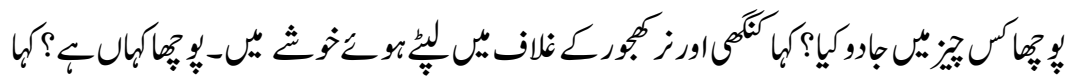

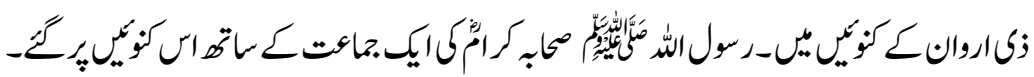

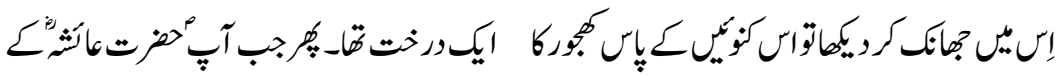

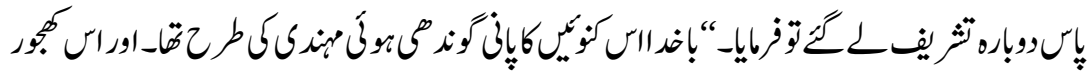

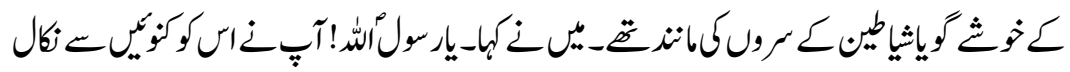

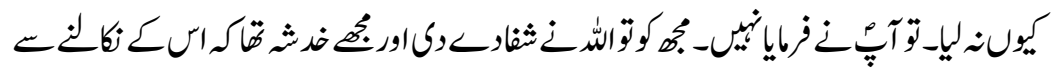

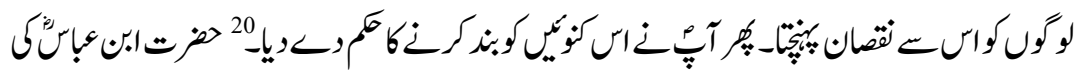

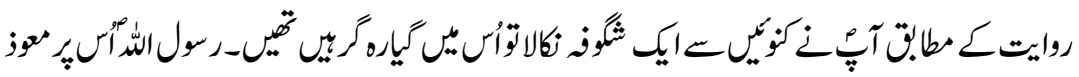

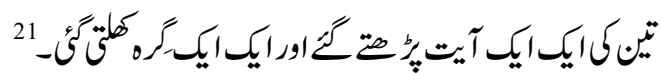

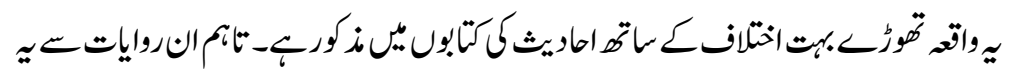

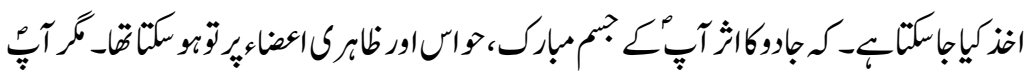

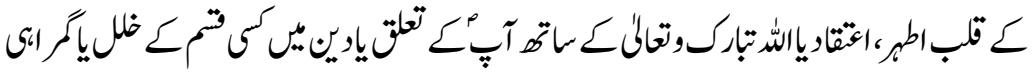

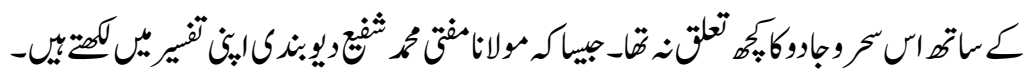

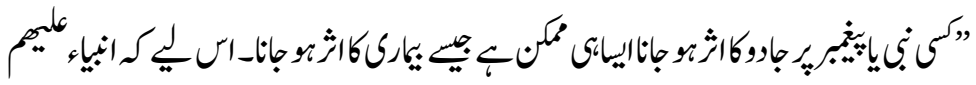

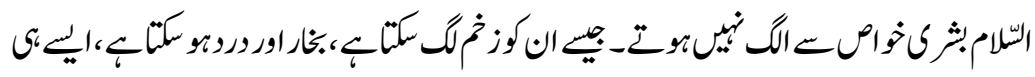

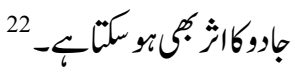

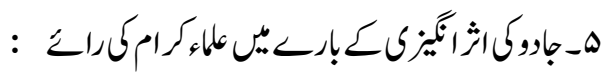

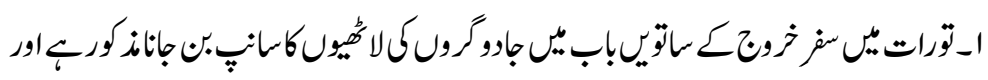

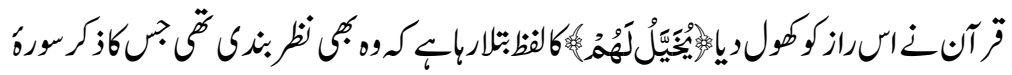

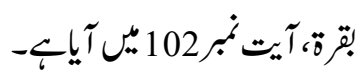

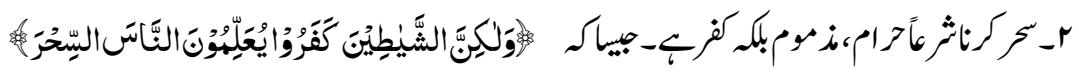

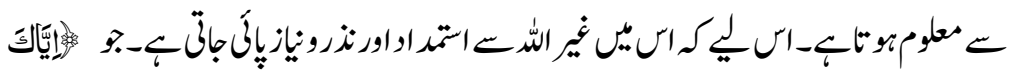

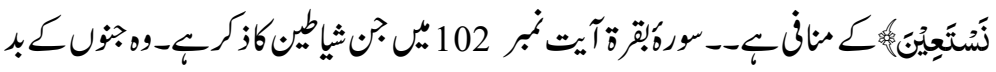

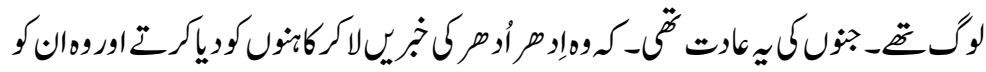

6 


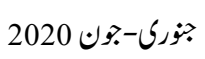

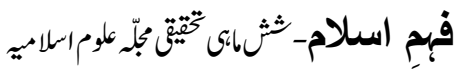

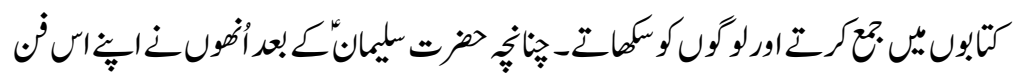

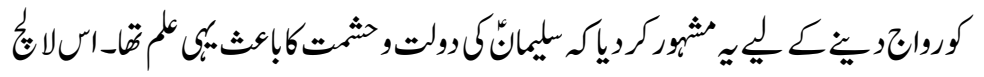

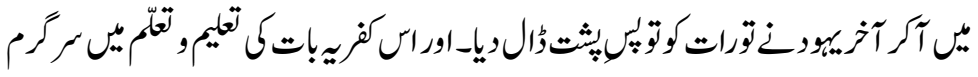

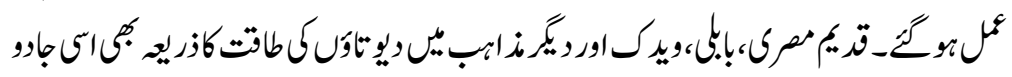

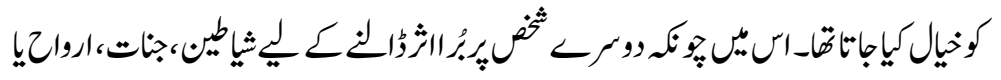

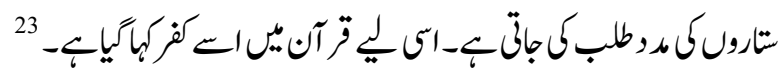

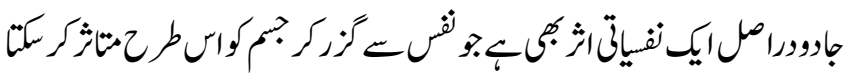

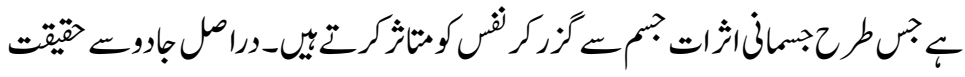

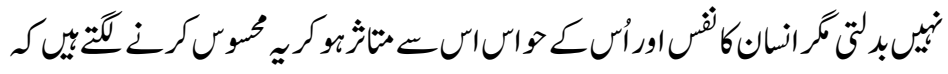

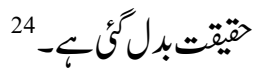

تحروجاووع عركات

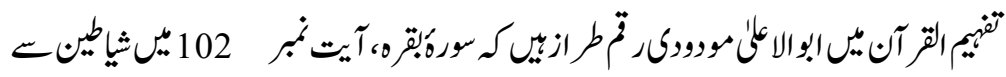

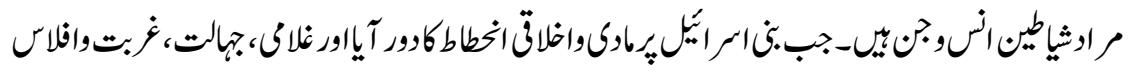

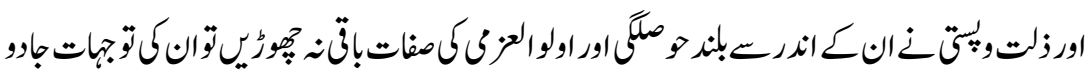

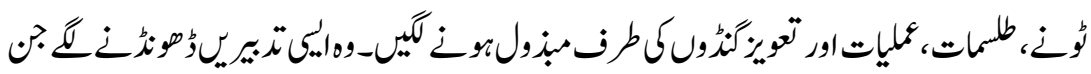

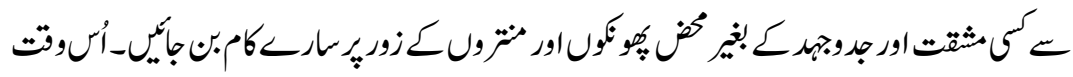

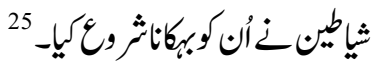

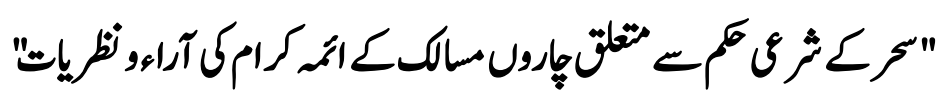

اـعلاحاحافع ثظريات

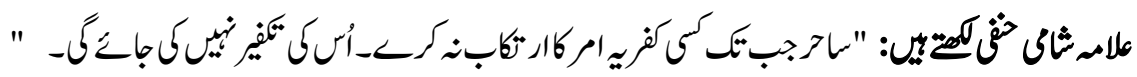

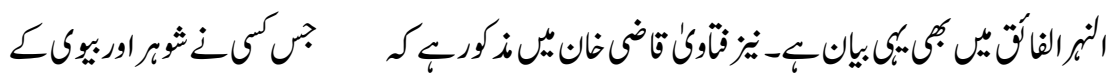

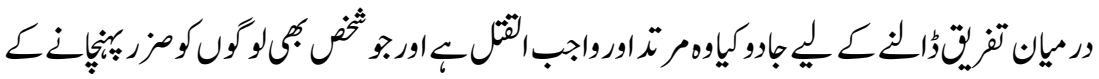

7 


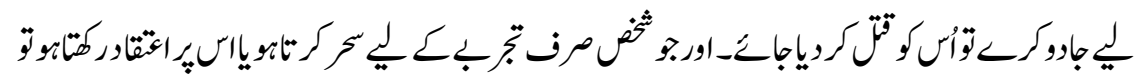

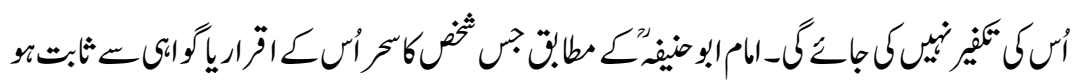

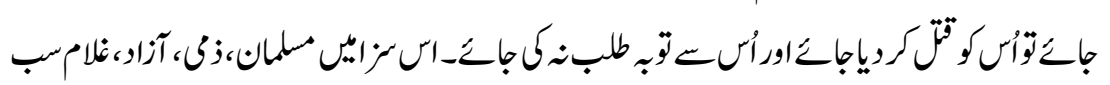

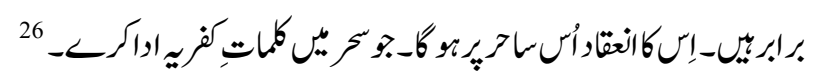

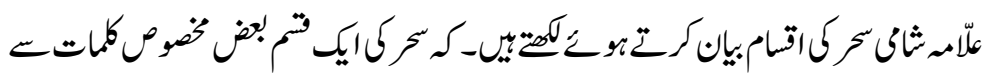

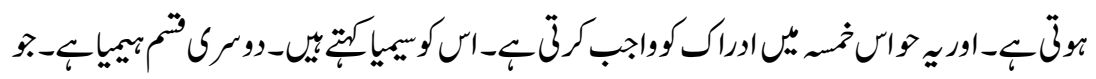

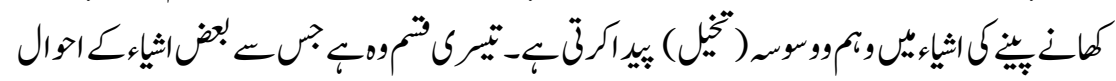

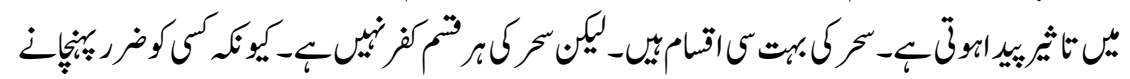

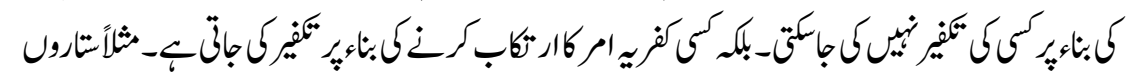

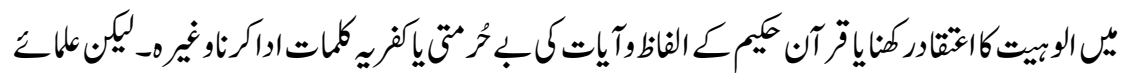

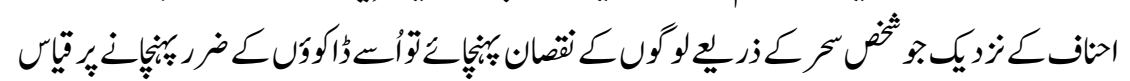

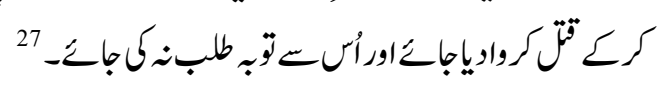

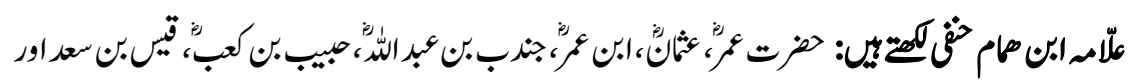

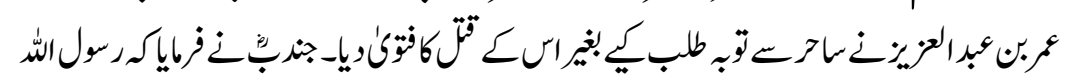

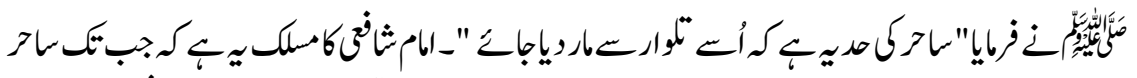

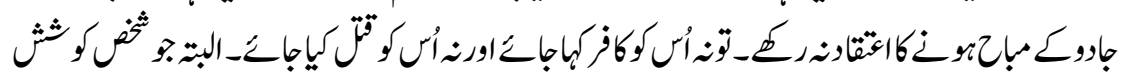

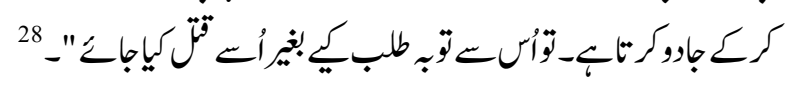

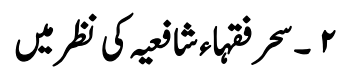

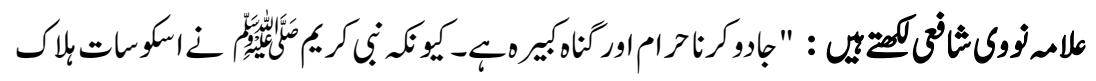

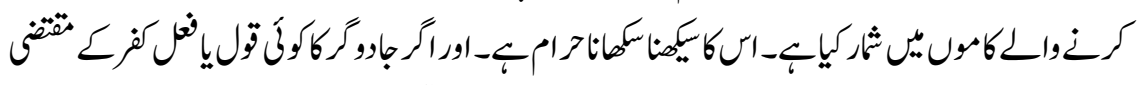

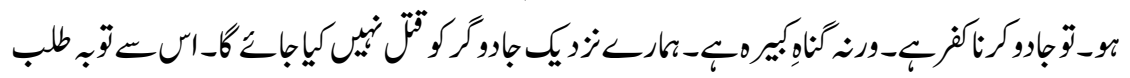

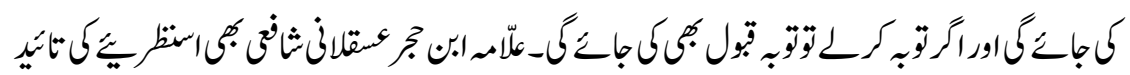

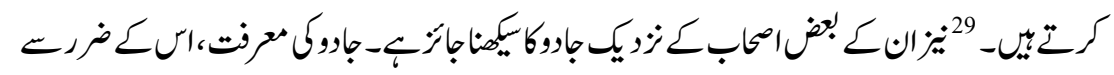

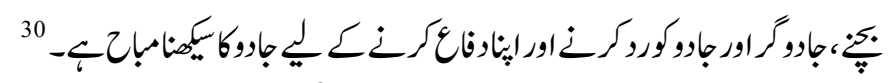




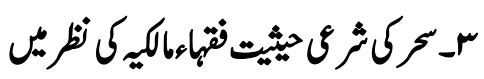

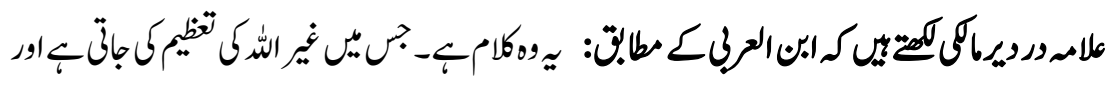

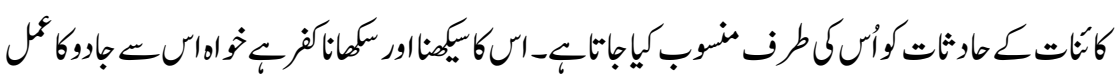

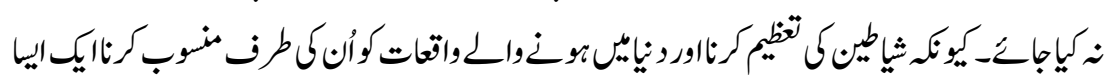

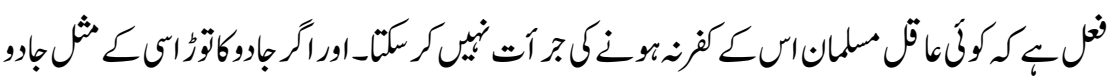

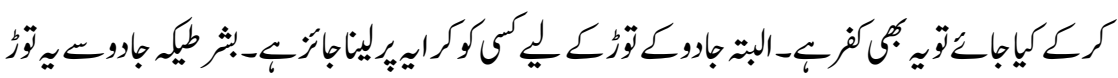

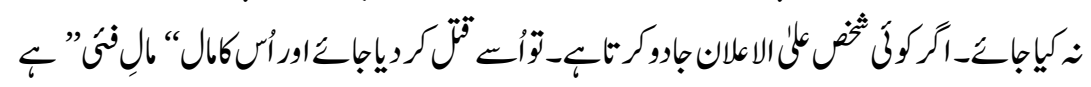

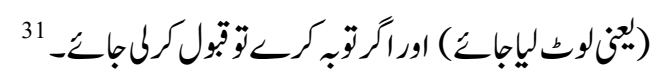

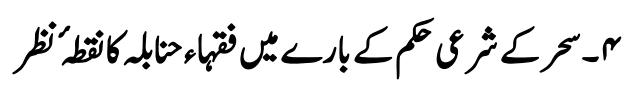

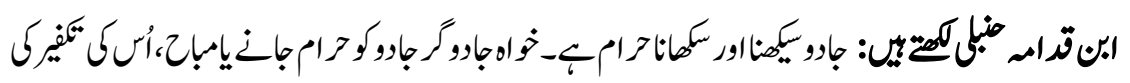

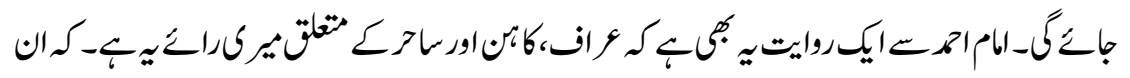

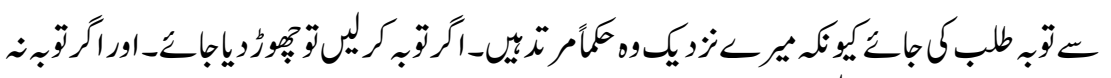

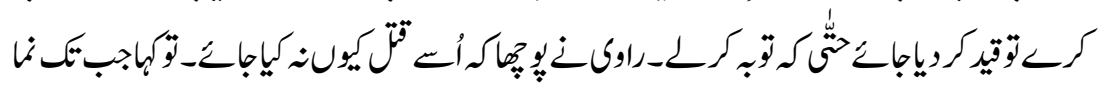

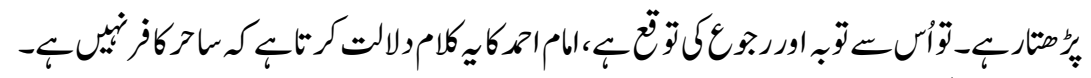

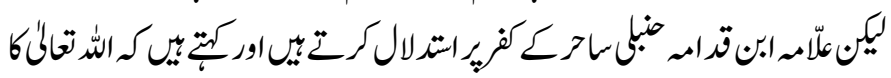

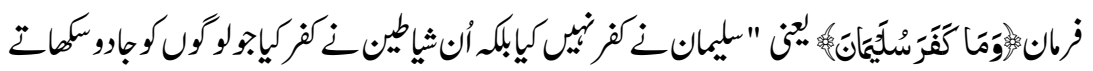

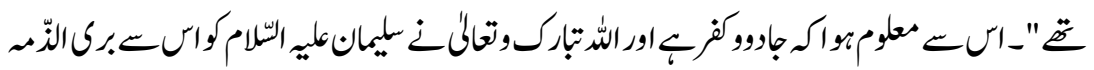

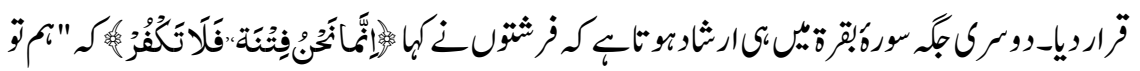

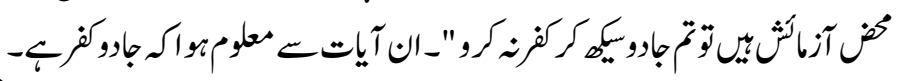

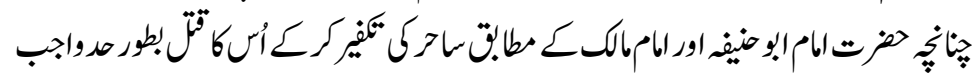

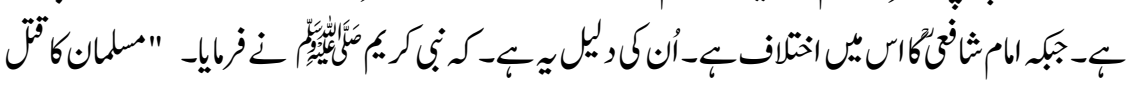

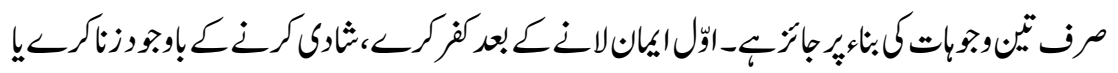

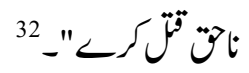




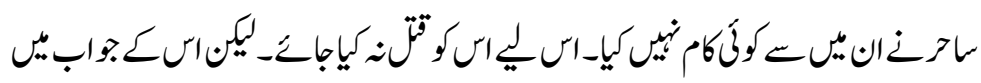

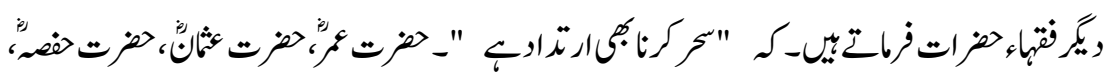

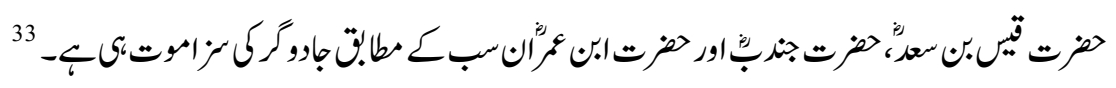

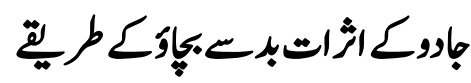

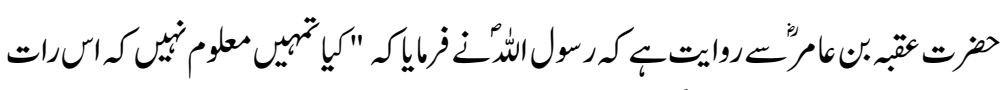

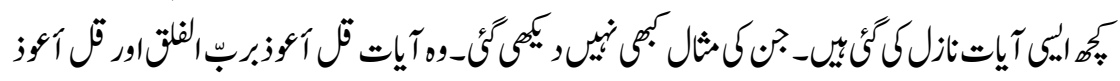

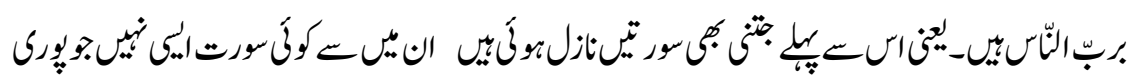

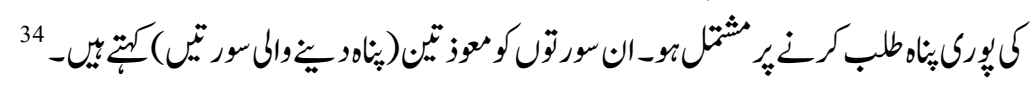

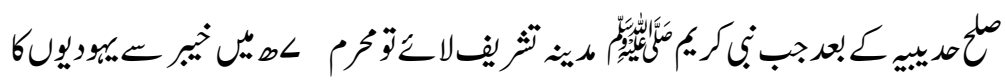

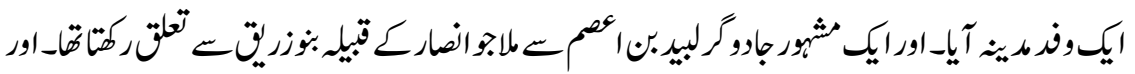

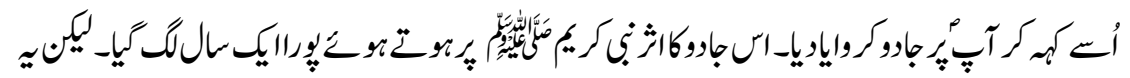

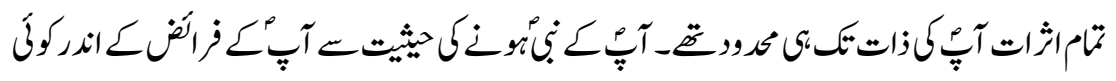

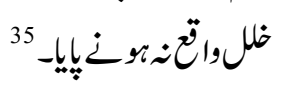

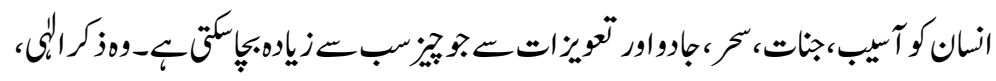

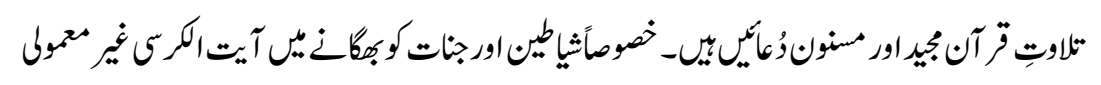

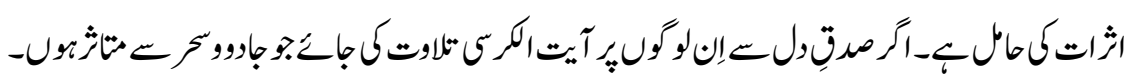

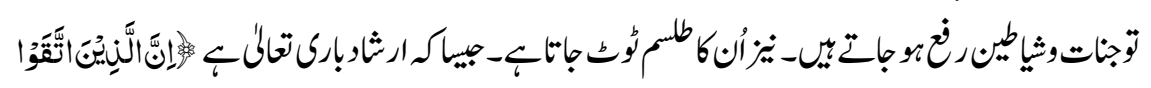

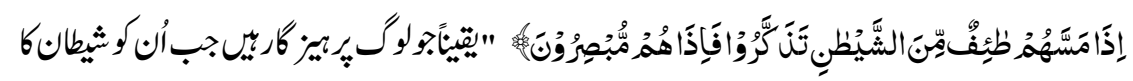

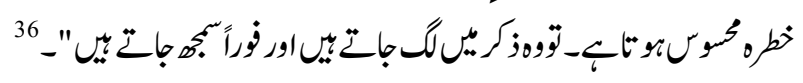

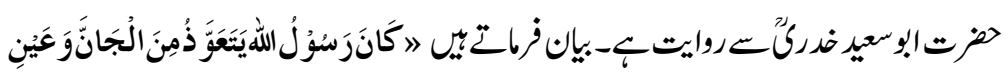

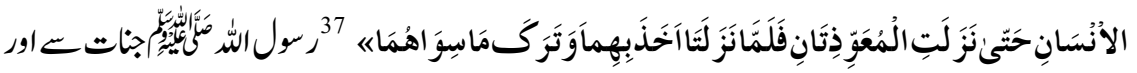

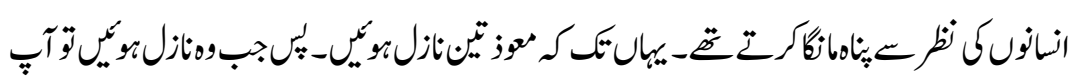

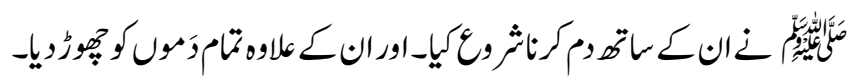




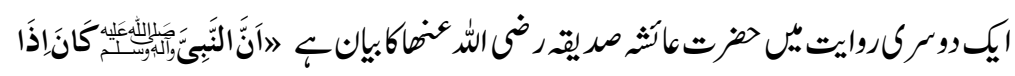

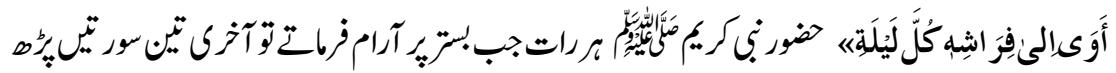

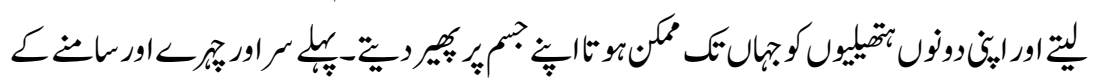

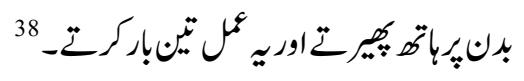

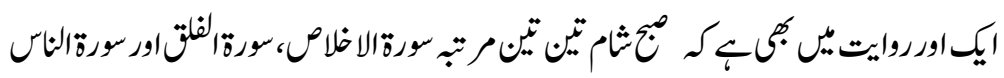

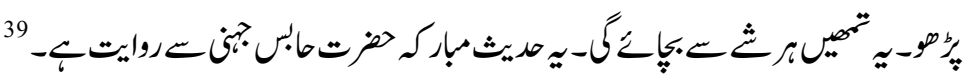

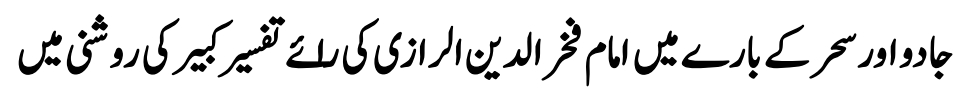

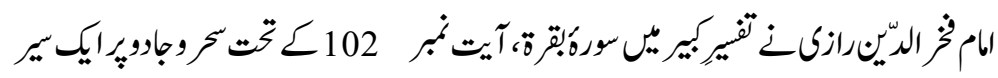

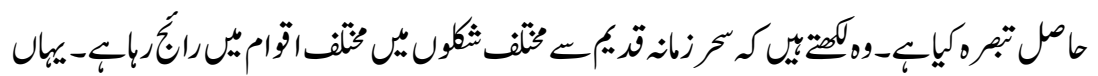

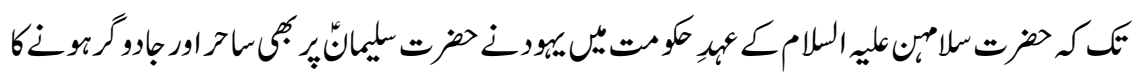

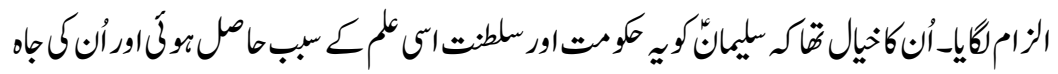

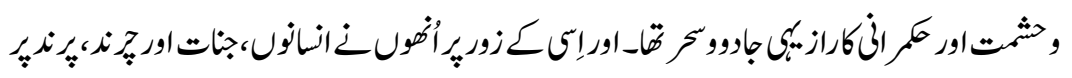

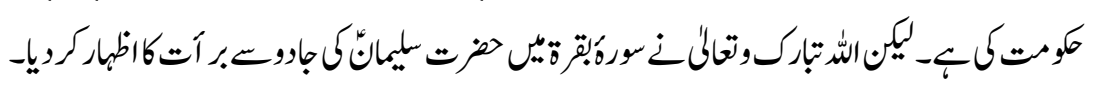

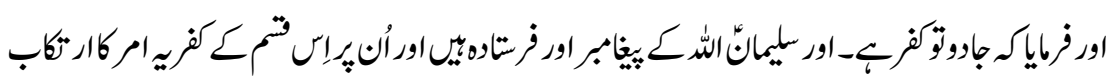

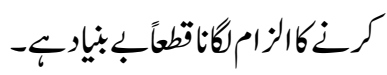

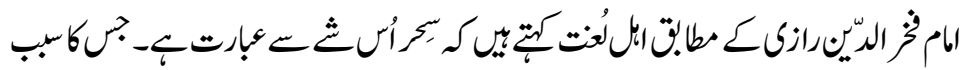

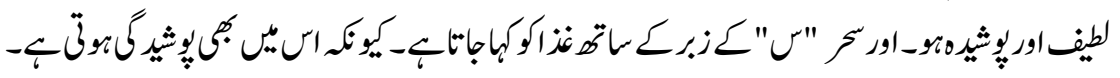

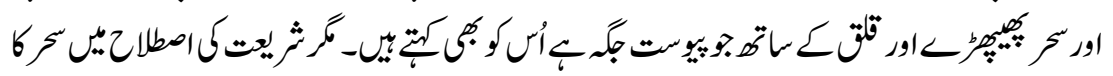

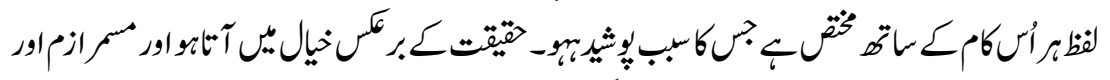

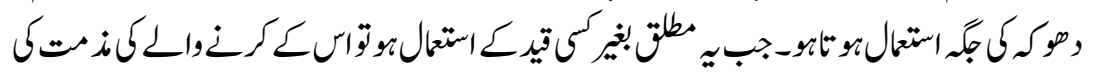

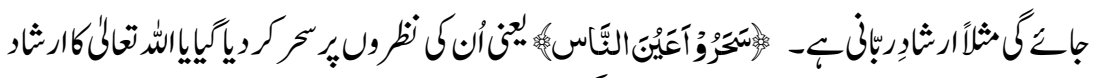

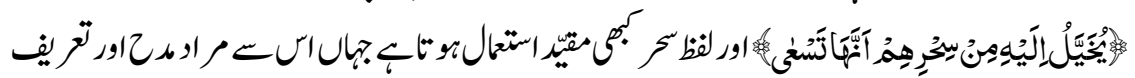

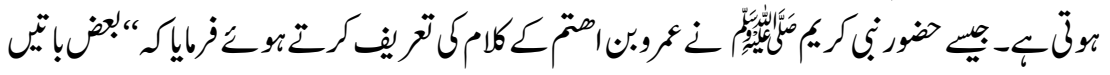

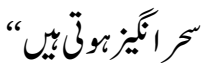




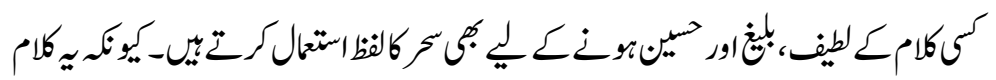

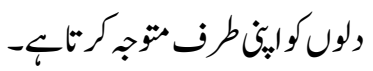

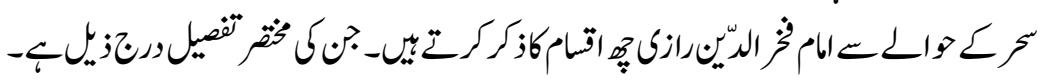

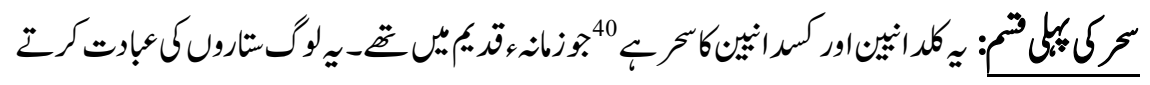


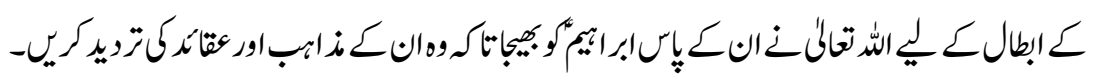

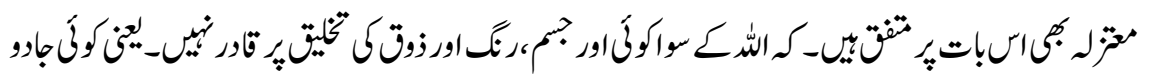

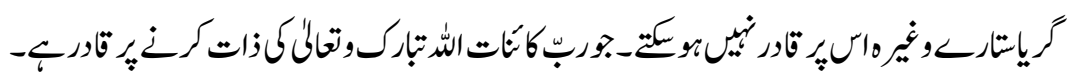

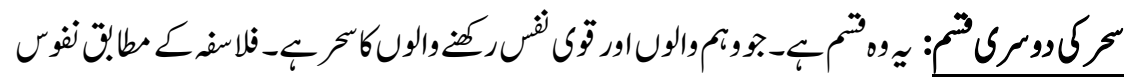

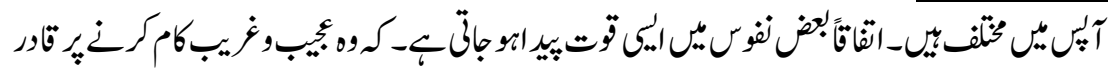

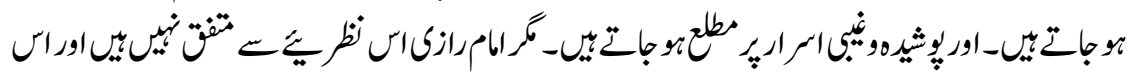

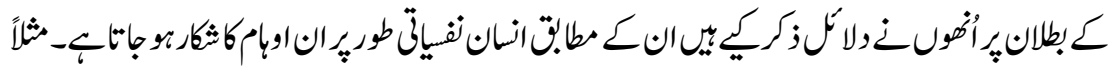

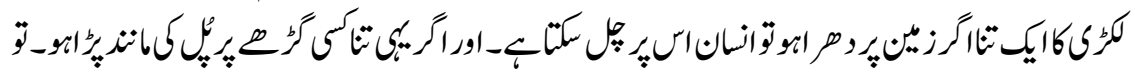

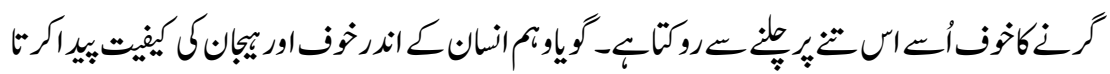

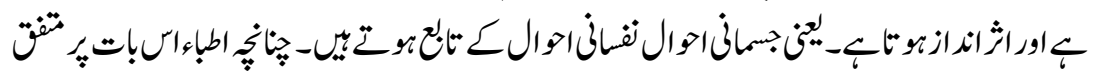

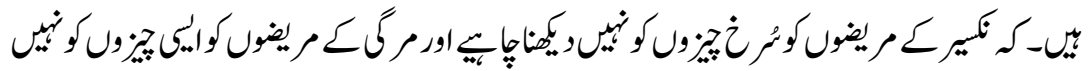

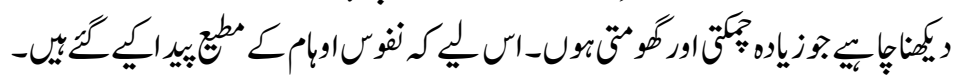

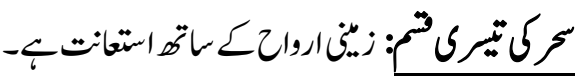

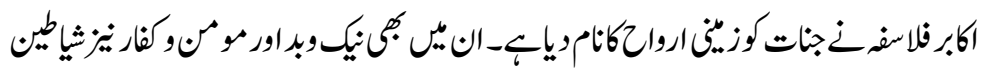

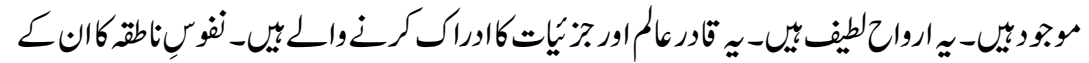

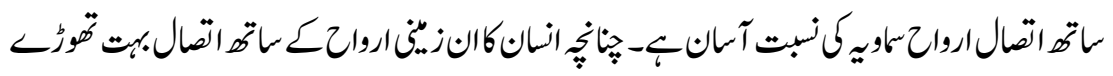

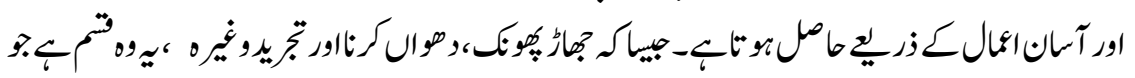

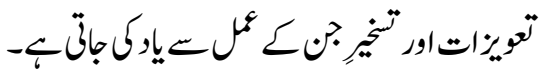




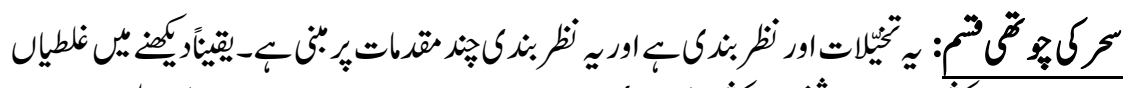

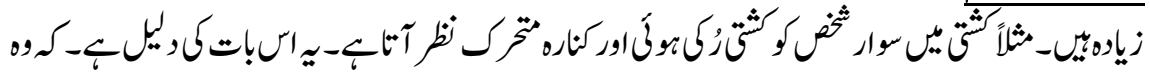

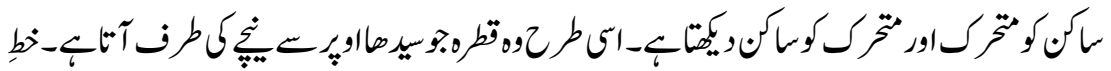

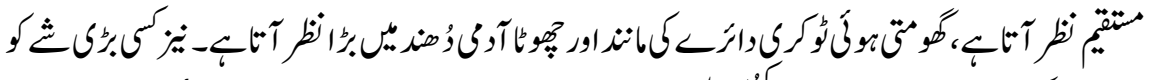

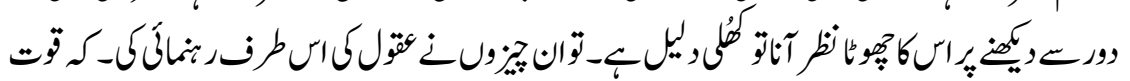

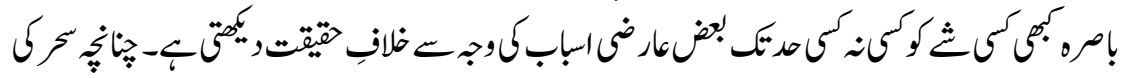

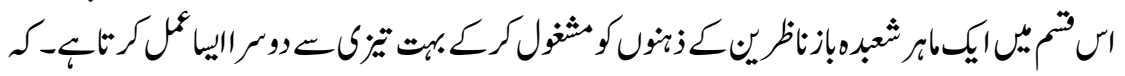

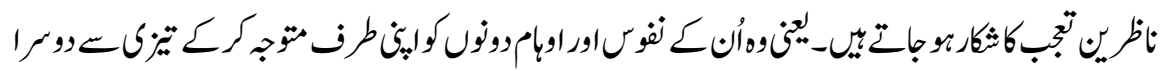

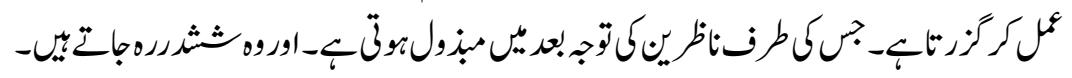

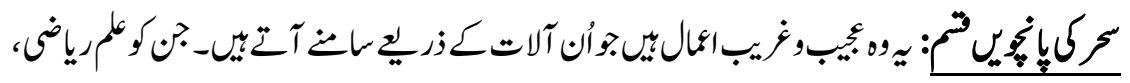

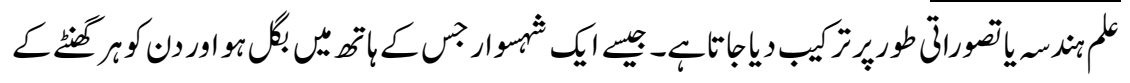

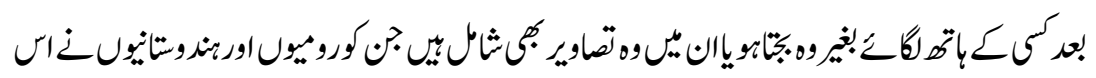

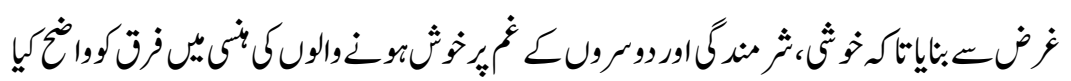

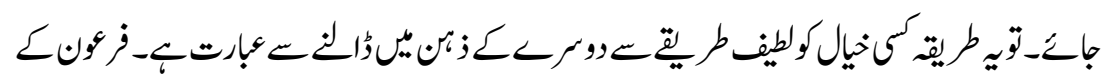

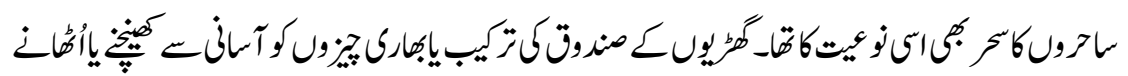

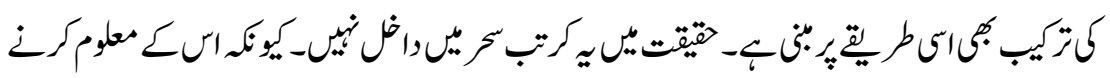

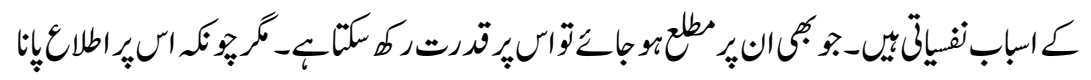

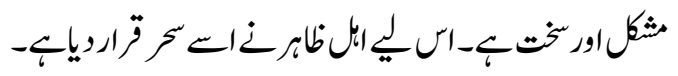

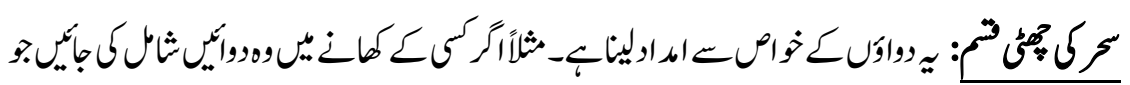

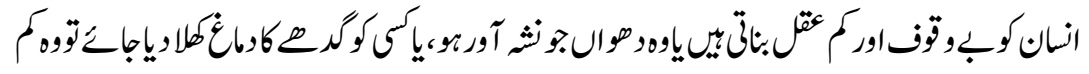

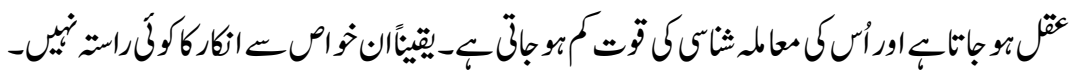

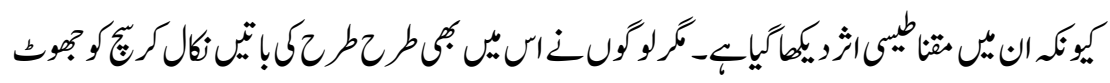

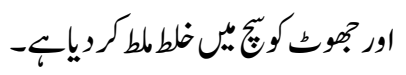




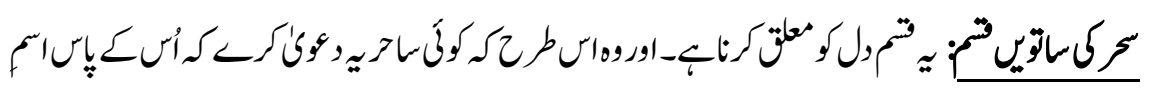

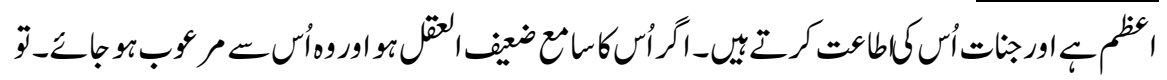

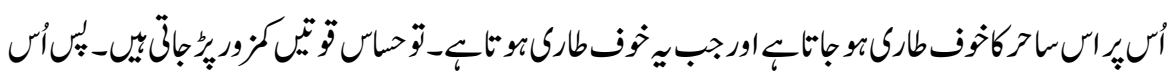

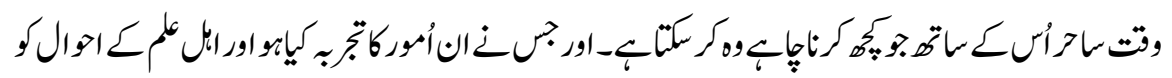

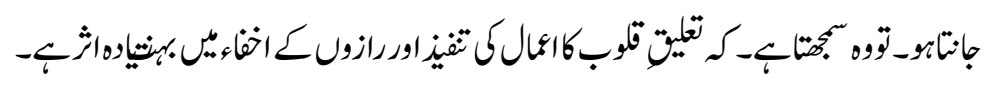

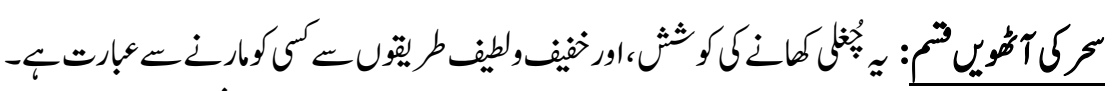

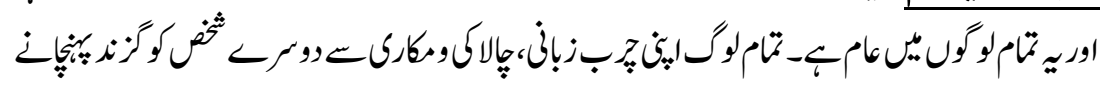

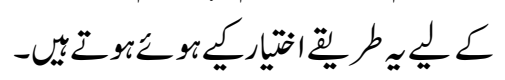

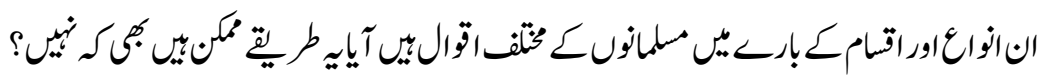

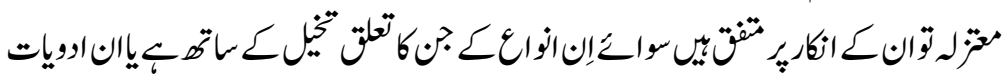

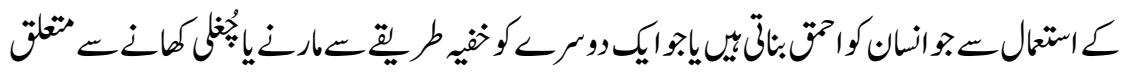

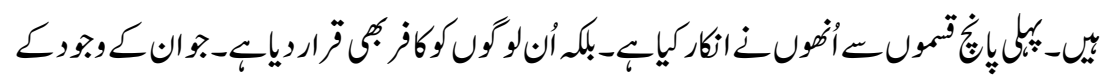

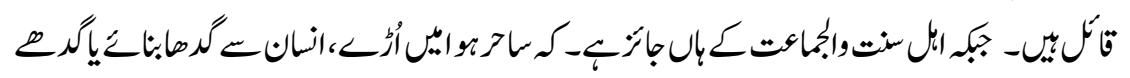

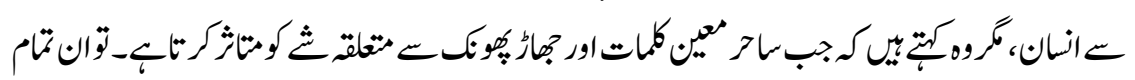

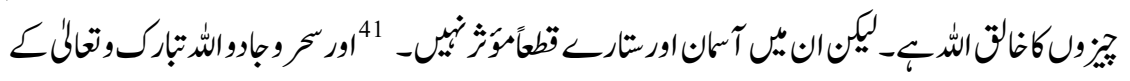

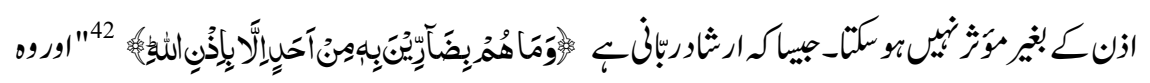

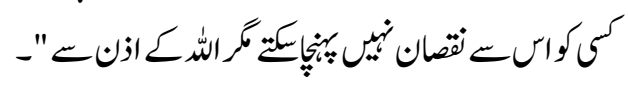

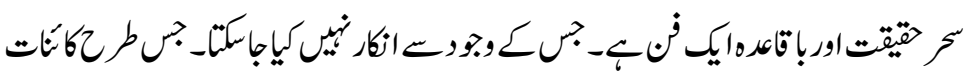

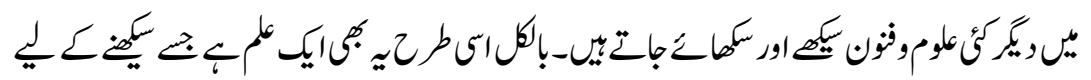

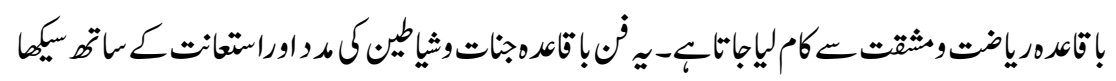

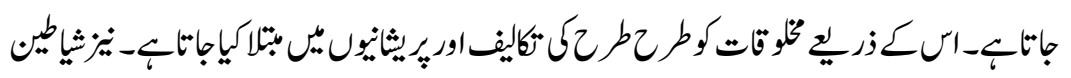

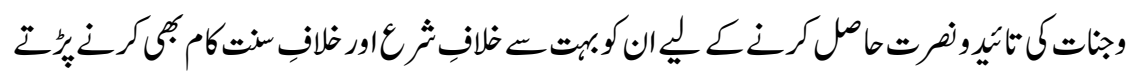




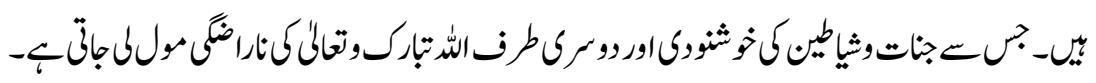

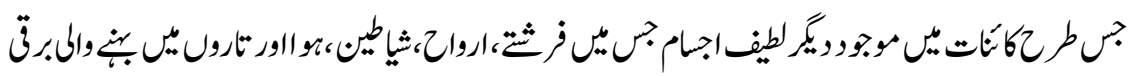

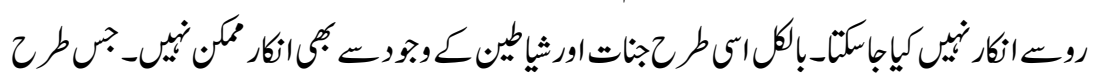

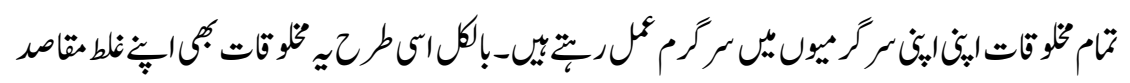

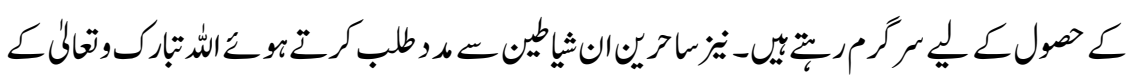

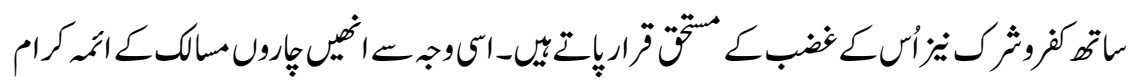

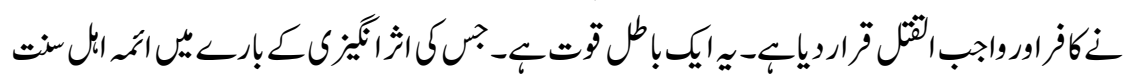

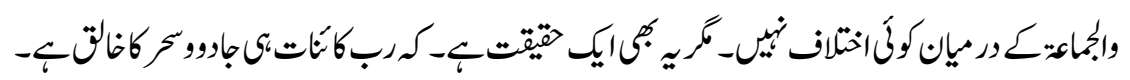

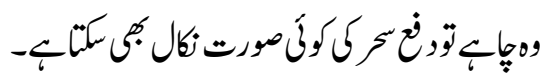

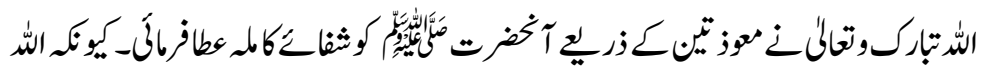

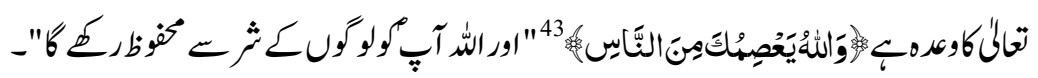

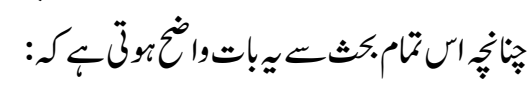

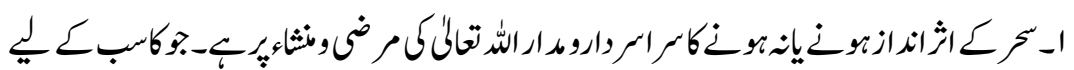

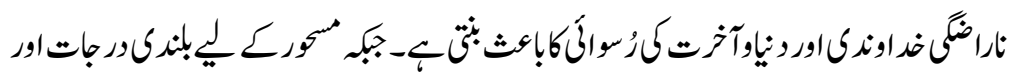

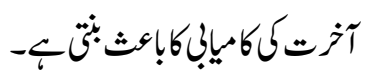

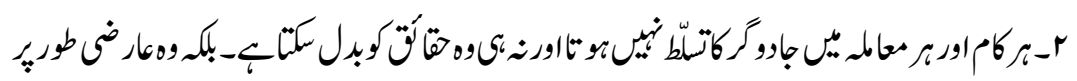

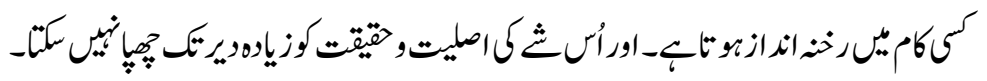

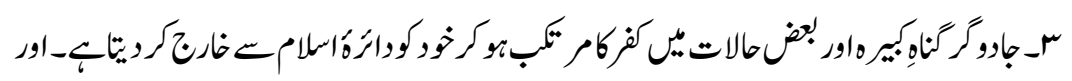

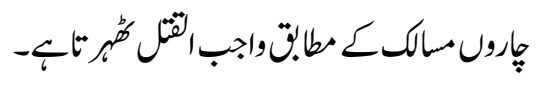

في مترمانعومصاور

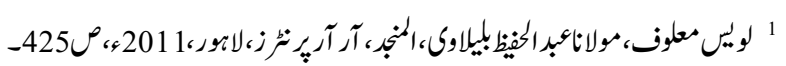

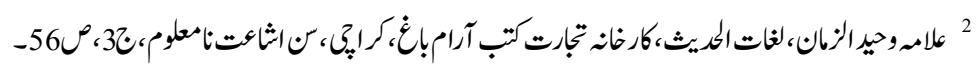

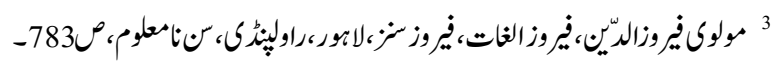




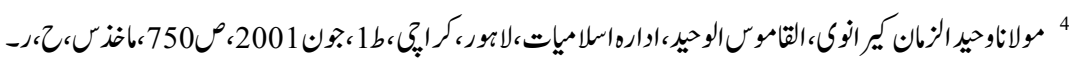

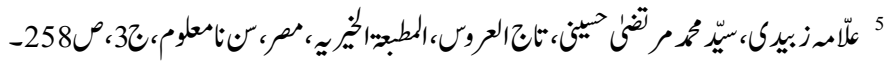

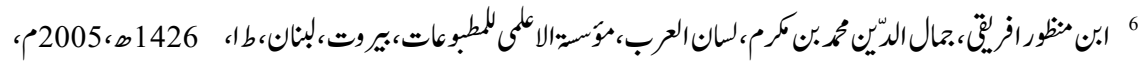
-1767-270

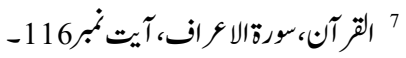

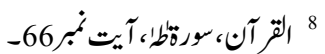

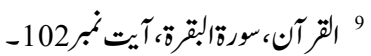

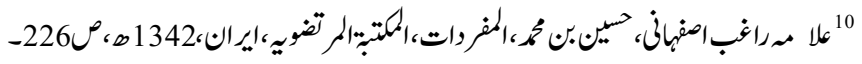

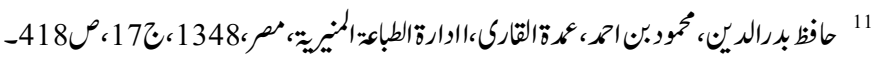

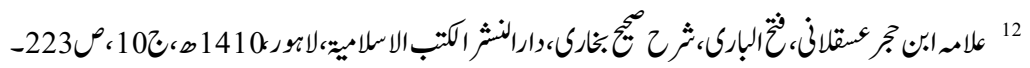

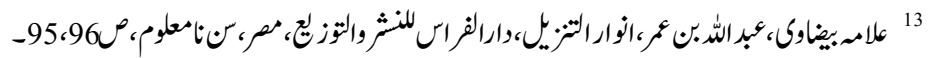

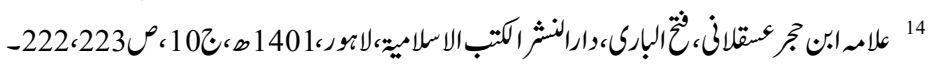

$$
\begin{aligned}
& 15 \text { الت آن، سورةطط، آيت نمبر 66ـ }
\end{aligned}
$$

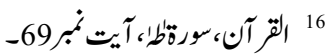

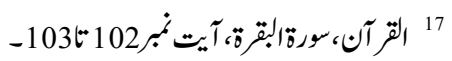

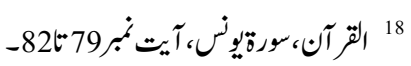

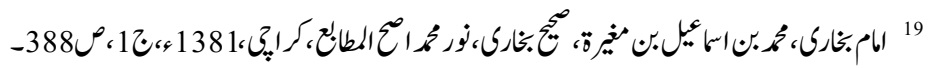

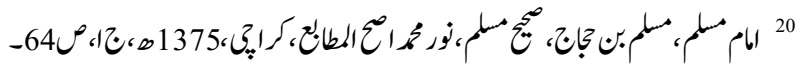

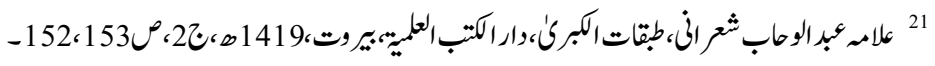

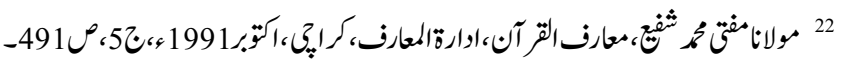

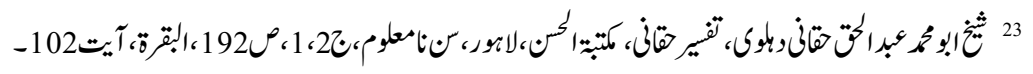

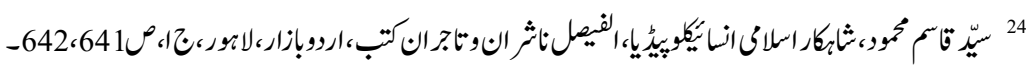

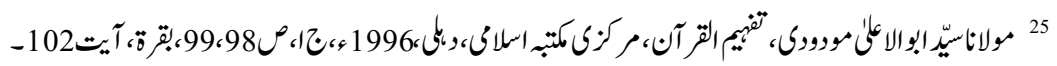

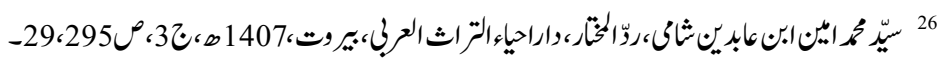

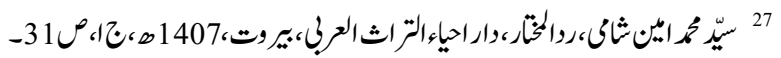

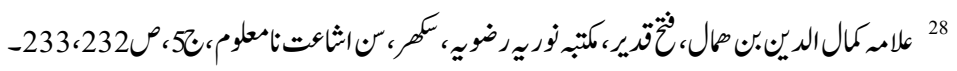

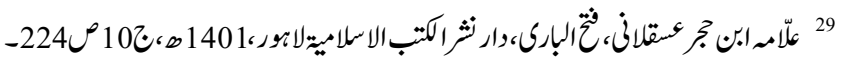




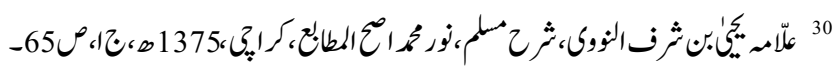

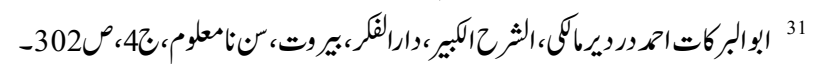

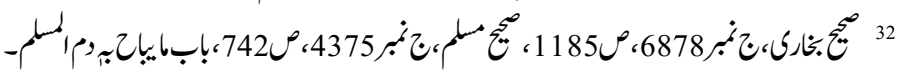

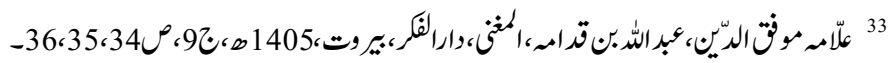

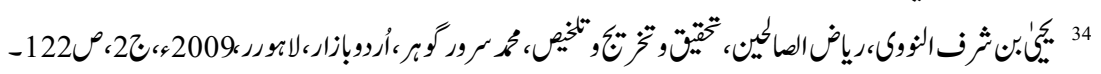

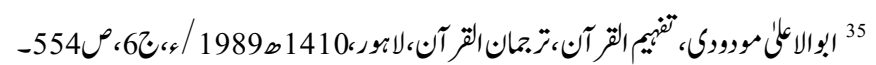

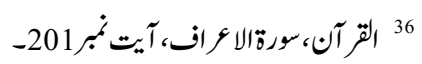

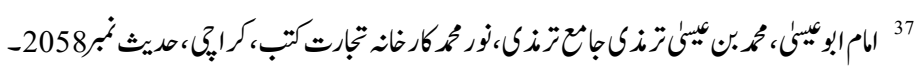

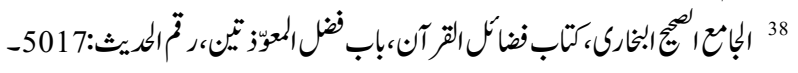

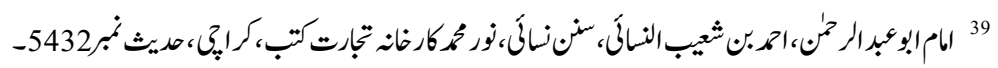
40

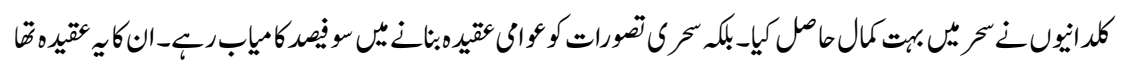

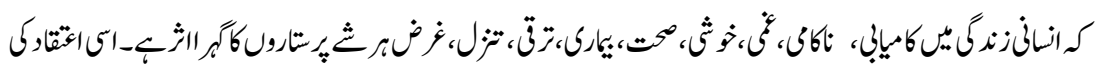

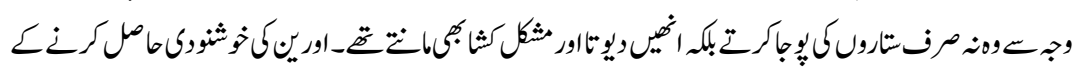

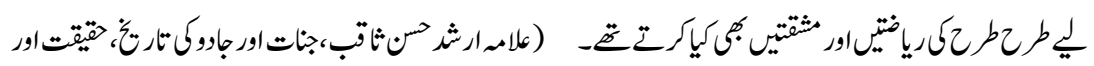

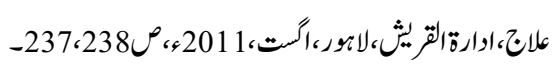

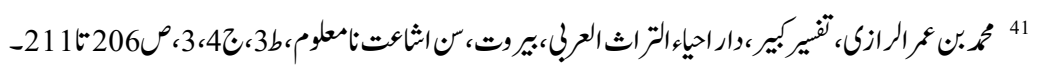
42

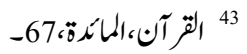

